\title{
Experimental Test Results of a Fabric Based Infrared Heating System on a Public Transport Vehicle
}

\author{
[ Hayri EREN, Mustafa EROL, Volkan KIRMACI]
}

\begin{abstract}
From past up to today motor vehicles use engine waste heat in order to warmup passenger compartment and to provide thermal comfort for the passengers. However, waste heat from the engine is sometimes not enough to provide required heat to the vehicle heating system especially in cold countries. In such cases, fuel burner heaters are very often preferred and used. When the coolant temperature is too low, then its temperature increased by burning fuel on the fuel burner heater and heated coolant is then pump to heat exchangers, located inside the passenger compartment, so that heating comfort is achieved. However, this proses both consumes extra fuel as well as increases exhaust emissions left to the atmosphere. On the other hand, when full electric vehicles are considered, which are increasing their shares in the market at every other day, because there is no internal combustion engine, there is no main heat source also. Hence, required heat has to be provided form the vehicle main batteries or from any other energy sources like ethanol or diesel. In this study, a novel electrical heating system with infrared capable fabric based heaters are assembled and tested on a public transport vehicle and results are presented.
\end{abstract}

Keywords - Fabric heating, public transport vehicle heating, innovative heating, novel heating, vehicle electrical heating,

\section{Introduction}

From very early stages of motor vehicles, passenger compartment heating is provided by heat exchangers which uses the engine coolant. Coolant both used to cool down the internal combustion engine (ICE), as well as to warm up passenger compartment via heating coils [1]. System stars with vehicle ICE, a basic schematic for a public transport vehicle can be seen on Fig.1 [2].

Hayri EREN

Anadolu Isuzu Otomotiv AS

Turkey

Mustafa EROL

Dokuz Eylul University

Turkey

Volkan KIRMACI

Bartin University

Turkey

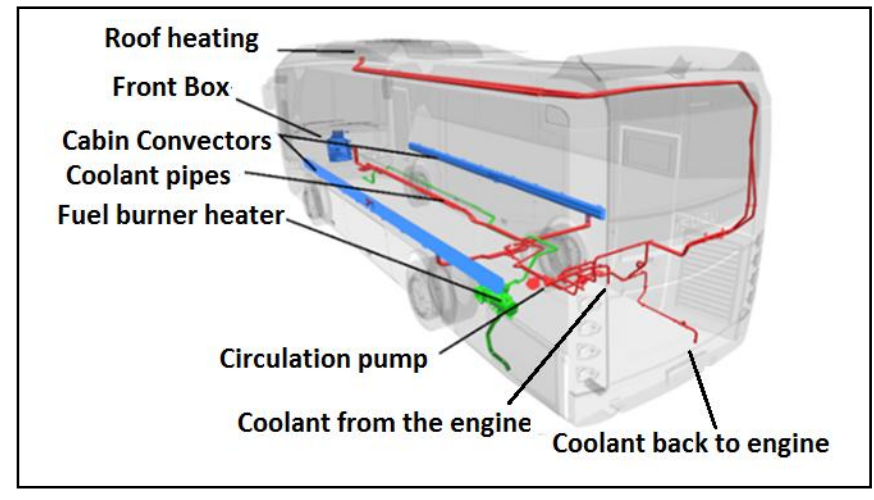

Figure 1. Vehicle heating system [2]

ICE waste heat, is transferred to coolant. Warmed up coolant is then pumped to fuel burner heater if available in the system. If the coolant temperature is below requested limits, its temperature increased by burning extra fuel in the fuel burner heater so that adequate heat is stored in the coolant. Hot coolant is then transferred to heat exchangers located in the passenger compartment via coolant lines. Hot coolant passes thru heating coils in the cabin so that cabin air is warmed up. After heat exchangers, coolant is then pumped back to the vehicle ICE and the process repeats $[1,2]$. However, especially during the initial warm-up period or when the weather is too cold, where engine waste heat is not enough to warm up passenger compartment, there has to be fuel burner heaters used in order to provide adequate heating to the coolant and to provide thermal comfort [3] for the passengers. Which means, extra fuel has to be consumed. Therefore, overall fuel consumption as well as exhaust emissions will be increased.

Especially when zero emission vehicles are considered, there is no internal combustion engine and hence no engine waste heat available. In such cases, alternative energy source has to be used like ethanol or diesel heaters or vehicle main batteries could be an option. When the main batteries are used, passenger compartment heating system could reduce vehicle range by $50 \%$ or maybe even more depending on the conditions (Fig.2, Fig. 3) [4, 5].

The reason for such major effect on energy consumption with available heating system is its effectiveness [2]. Because current heating system on vehicles is based on convective heating, it does include many steps and therefore overall effectiveness of the system is reduced considerably. Such that, in order to warmup passenger compartment, coolant is warmed up first using electrical power, hot coolant then pumped to heat exchangers inside the cabin. Then cabin air is warmed up by using heat exchangers so that, passenger's thermal comfort is provided. Each step has its own effectiveness and losses. Therefore overall system effectiveness is considerably low. 


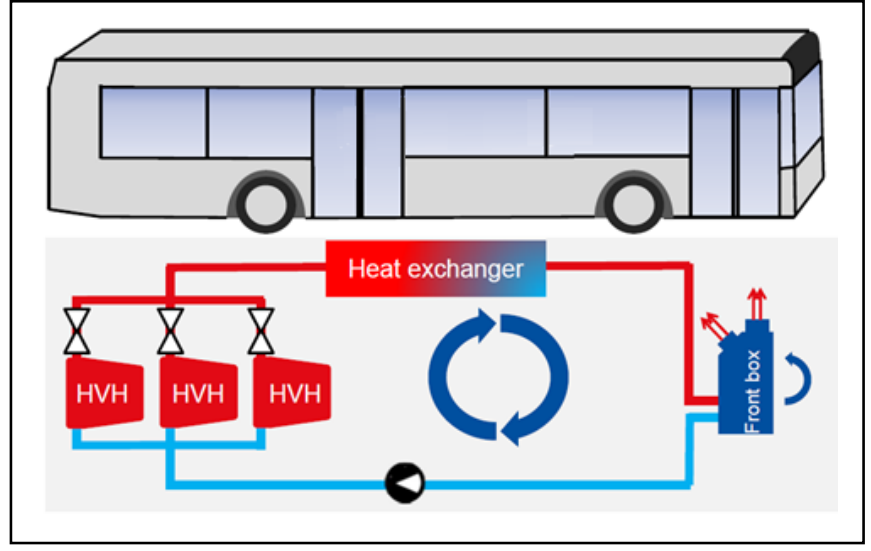

Figure 2. Electric bus heating system

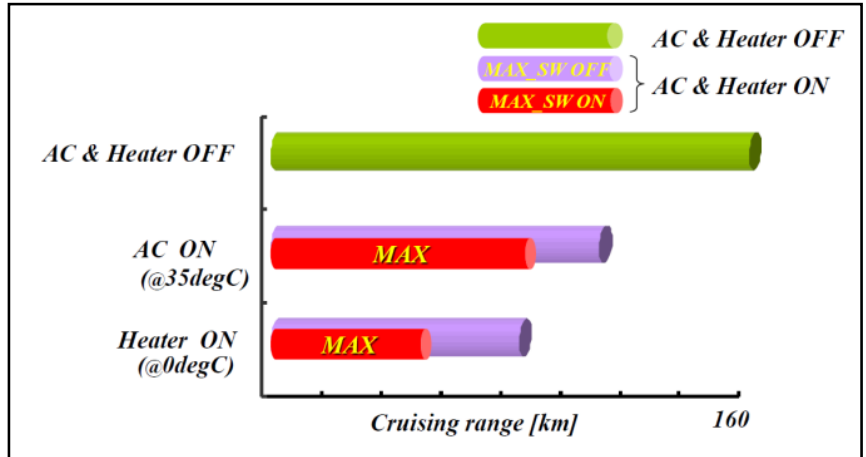

Figure 3. Passenger compartment heating system effect on electrical vehicle batteries [4]

\section{Experimental Study}

In this study, radiant heating method [6,7], which heats passengers and objects directly rather than heating the air first and expecting the hot air to warm up the passengers [8], is used on a public vehicle heating system and tested.

Heating system itself, is a fabric based heating system (will be called heating fabric), which consists of modified polyester fabric matrix and modified carbon fibres as resistance [2]. Heating fabric is assembled on to interior surfaces of the vehicle like roof inner surface, floor, body sides and seat surfaces as shown on Fig.4.

In order to reach the best interior thermal comfort, different surface temperatures and hence different heating power has been used on different parts. Heating fabrics has been connected to each other either serially or parallel depending on their voltage requirement to provide required heating power and surface temperature.

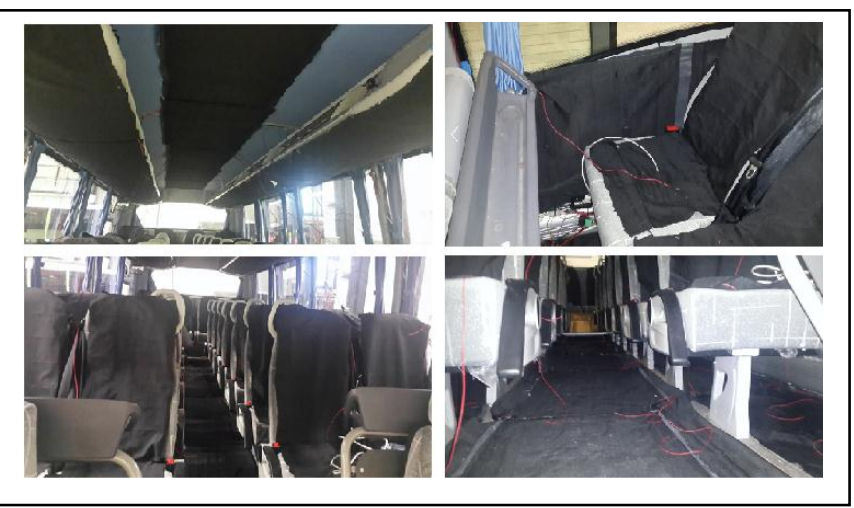

Figure 4. Heating surfaces applied in to test vehicle
Because the system itself is an electrical system, an auxiliary power source has been used to power the system during tests.

\section{Results and Discussions}

Performance tests has been conducted in a test chamber. Vehicle has been soaked at $-7{ }^{\circ} \mathrm{C}$ during 8 hours. After 8 hours soak, heater performance test has been conducted during 2 hours at $-7^{\circ} \mathrm{C}$. During the test, all heating fabrics has been set to max power, and no pre heating applied. Auxiliary power system has been used to power the heating fabrics along the test. Thermal imaging results has been provided from vehicle interior trim and can be seen on Fig.5.

Beside thermal images, objective test data is also collected during maximum heater performance test and result are presented on Fig. 6. Temperatures are measured at head level and foot level using thermocouples. According to test results, both foot level and head level air temperatures has been reached the radiation heating comfort zone [7] around 60-65 minute at valid test conditions.

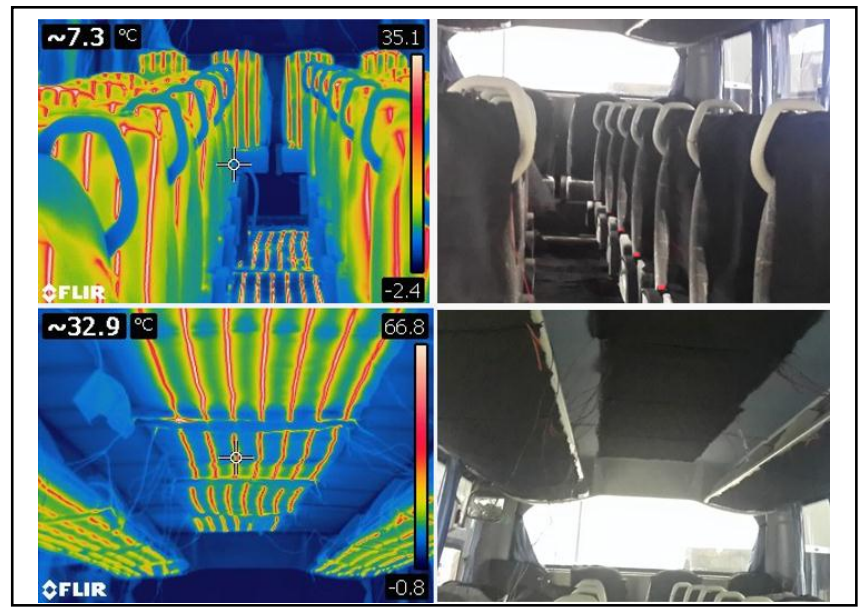

Figure 5. Thermal images of heating fabrics at performance test

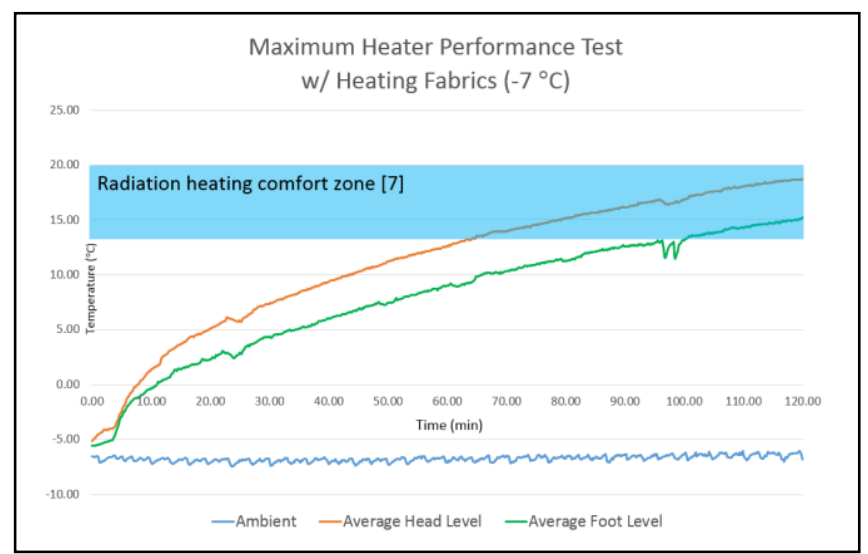

Figure 6. Maximum heater performance test with heating fabrics

\section{Conclusion}

In this study, fabric based radiant heating system on vehicles has been designed and successfully tested at $-7{ }^{\circ} \mathrm{C}$ ambient. It can be said that its worth studying more on radiant heating in electrical vehicles since the results are 
promising and can be an option on reducing energy consumption on electrical vehicles.

\section{Acknowledgment}

This research is financially supported by Scientific and Technological Research Council of Turkey (TÜBİTAK) and Anadolu Isuzu Otomotiv AŞ. (AIOS).

\section{References}

[1] Eren H., Kirmacı V., "Infrared Heating System Design on Commercial Passenger Vehicles”, IMSTEC'16 (2016), p.745-748.

[2] H.Eren, V. Kirmaci, M. Erol, A. Yavas, H. Duran, Y. Ozturk, "New Generation Fabric Based Electrical Heating Systems: A Case Study For Public Transport Vehicles", ICSTEM, Prague, Czech Republic, 2017.

[3] ASHRAE, Thermal environmental conditions for human occupancy, ANSI/ASHRAE Standard 55, 1992.

[4] Umezu, K. ve Noyama, H., "Air-Conditioning System for Electric Vehicles (i-MiEV)", SAE Automotive Refrigerant \& System Efficiency Symposium., 2010.

[5] Leighton, D., Combined "Fluid Loop Thermal Management for Electric Drive Vehicle Range Improvement”, SAE Int. J. Passeng. Cars - Mech. Syst. / Volume 8, Issue 2, July 2015.

[6] BMW Group Innovation Day: Efficient Dynamics, Intelligent Energy Management: heat pump, infrared heating surfaces and the second generation of the air vent control help to save energy, 2012.

[7] Bäuml T., Dvorak D., Frohner A., Simic D., "Simulation and Measurement of an Energy Efficient Infrared Radiation Heating of a Full Electric Vehicle". In Vehicle Power and Propulsion Conference (VPPC), IEEE 1-6, 2014.

[8] Ene C.A, Stancila M, Ivanescu M, Neacsu A.C., "Studies on Infrared Radiation Heating for Increasing Thermal Comfort”, DPR Dräexlmaier, Romania; Leoni Wiring Systems SRL, Romania, University of Pitesti, Romania, Automobile Dacia SA - Groupe Renault, Romania, 2013.

About Author (s):

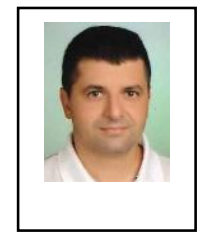

[Hayri Eren was born in Bartin, Turkey in, 1975. He graduated from Trakya University in 2007 with a bachelor degree in Mechanical Engineering. He get MSc from İstanbul Technical University at Automotive Engineering in 1999 and he Started his $\mathrm{PhD}$ at Bartın University in 2014. He started his professional life in Automotive R\&D department in 2000 and still employed in Anadolu Isuzu R\&D. He is expertise on vehicle interior trim and HVAC systems]

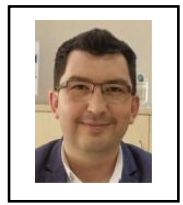

[Dr. Mustafa Erol was born in Ankara, Turkey in 1983. He graduated from Dokuz Eylul University in 2007 with a bachelor degree in Metallurgical and Materials Engineering. He get MSc and $\mathrm{PhD}$ degrees from Dokuz Eylul University on Metallurgical and Materials Engineering in 2009 and 2014, respectively. He has been working as an assistant professor in the Department of Metallurgical and Materials Engineering at Dokuz Eylul University in Izmir. His area of research is as follows: heat releasing materials, semiconducting and functional materials, photocatalysis, and nanomaterials.]

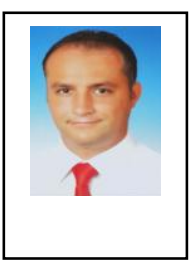

[Dr. Volkan KIRMACI was born in Izmir, Turkey in 1978. He graduated from Gazi University in 2007 with a bachelor degree in Mechanical Education Department. He gets MSc and $\mathrm{PhD}$ degrees from Gazi University on Mechanical Education

Department in 2002 and 2008, respectively. He has been working as an assistant professor in the Department of

Mechanical Engineering at Bartın University in Bartın. His area of research is as follows: heat transfer, Thermodynamics, cooling, and energy.] 